\title{
THE THEORETICAL SIMULATION OF AXIAL VIBRATIONS IN FINITE CYLINDRICAL PIEZOELECTRIC SHELL MADE OF THE TRIGONAL (3M) CRYSTAL
}

\author{
${ }^{1}$ H. Zeynali, ${ }^{2}$ B. Jazi and ${ }^{3}$ R. Karimi \\ ${ }^{1}$ Department of Physics, Islamic Azad University of Kashan, Blvd. Ravand, Kashmir, Iran \\ ${ }^{2}$ Department of Laser and Photonics, Faculty of Physics, University of Kashan, Kashan, I.R. Iran \\ ${ }^{3}$ Department of Physics, Islamic Azad University of Natanz, Natanz, Iran
}

Received 2012-08-03, Revised 2012-08-03; Accepted 2013-02-15

\begin{abstract}
The axial vibration in a thin layer of finite cylinder made of trigonal $(3 \mathrm{M})$ piezoelectric crystal are investigated. By using a closed form solution of the equations of motion and applying new boundary conditions the effects of the geometrical dimensions, axial hydrostatic pressure and electrostatic potential along the axis of the cylinder shell on oscillation frequency and amplitude of spatial vibrations are simulated.
\end{abstract}

Keywords: Finite Cylindrical Piezoelectric Shell

\section{INTRODUCTION}

Piezoelectric materials are now widely used in many fields of engineering. Thanks to their ability to convert electrical in mechanical energy and vice versa, they serve as sensors, actuators and transducers. Piezoelectric components and materials are integrated into complex smart structures or embedded as layers or fibers into multi functional composites. The interested reader is referred to recent conference proceedings (Gabbert and Tzon, 2001; Brebbia et al., 1998) for further information. It is well known that ceramic cylindrical piezoelectric shells are often used in underwater sound navigation and ranging (sonar) transducers (Stansfield, 1991; Wilson, 1988). Axially polarized shells are used in projectors and radially polarized shells used in non-neutral electron beam diagnostics (Jazi et al., 2006; Feriedom, 1968) and hydrophones (Hison et al., 2005; Kraus et al., 2003; Pasquale, 2003; Bartlett et al., 2001; Gafsi et al., 1997; Inaudi et al., 1994). Projectors and hydrophones are underwater analogues of loud speakers and microphones respectively. One notable civil engineering application of piezoelectric sensors is in structural health monitoring
(Hison et al., 2005; Kraus et al., 2003; Pasquale, 2003; Bartlett et al., 2001; Gafsi et al., 1997; Inaudi et al., 1994; Kawiecki, 1999). Models of piezoelectric shells are necessary not only to model transducer, but also to determine the material properties of the shells. By a closed form solution of the equations of motion and boundary conditions the effects of the dimensions of the shell and the piezoelectric coefficients on the axial vibrations are investigation in (Ebenzer and Ramesh, 2003; Yang and Batra, 1995). The interest in these problems arises because of their applications as resonators. Vibrations of a circular cylindrical piezoelectric shell, with deformations assumed to be either axisymmetric or with the tangential displacement taken to be zero and made of ceramics poled in various direction, have also been studied in (Haskins and Walsh, 1957; Shud'ga et al., 1984). The frequency spectra of axial vibrations of cylindrical piezoelectric shells have significant variation, even when they are made in one batch. This causes a variation in the characteristics of transducers. Quantities that can be measured easily in the case of piezoelectric shells are, for example, the frequencies at which resonances and anti-resonances

(c) 2013 H. Zeynali, B. Jazi and R. Karimi. This open access article is distributed under a Creative Commons Attribution (CC-BY) 3.0 license which permits unrestricted use, distribution, and reproduction in any medium, provided the original work is properly credited. DOI: 10.3844/pisp.2013.13.22 
occur when the shell is electrically excited. Here we have presented a theoretical simulation for the axial mechanical vibrations of finite cylindrical piezoelectric shells. It must be noted that comparing with (Ebenzer and Ramesh, 2003; Yang and Batra, 1995) we will study the frequency spectrum and its dependency on the geometrical dimensions, axial hydrostatic pressure and electrostatic potential along the axis of cylindrical shell made of trigonal $(3 \mathrm{~m})$ piezoelectric crystals. This study is organized in four sections and an appendix. The introduction was presented as section 1. In section 2 the geometrical configuration and the basic governing equations of finite cylindrical shell of trigonal piezoelectric crystal are presented. In section 3 by using a closed from solution of the equations of motion the frequency spectra and its dependence to the geometrical dimensions, hydrostatic pressure and electrostatic potential along the axis of this system are investigated. In this section the graphs of amplitude squared of spatial vibration versus the length of cylindrical piezoelectric in different configurations are presented. Finally, in section 4 a summary and conclusion is presented.

\section{CONFIGURATION AND GOVERNING EQUATIONS}

Here we consider a thin shell of cylindrical piezoelectric made of the trigonal $(3 \mathrm{M})$ crystal shown in Fig. 1. The thickness of shell $\Delta$ is much smaller than the length of the cylinder $\mathrm{L}$ and the mean radius $\mathrm{R}_{\mathrm{p}}$ of the shell i.e., $\left(\Delta<<\mathrm{L}, \mathrm{R}_{\mathrm{P}}\right)$. The up and the down parts of the piezoelectric tube are fixed at electrostatic potentials $\phi_{\mathrm{u}}$, $\phi_{\mathrm{d}}$ and hydrostatic pressures $\mathrm{P}_{\mathrm{u}}, \mathrm{P}_{\mathrm{d}}$, respectively. Furthermore it is assumed that the down part has no spatial displacement and it locked by a hard holder at $\mathrm{z}=$ 0 . The trigonal piezoelectric $(3 \mathrm{M})$ crystals are defined by the elastic stiff-nesses tensor Equation 1 (Vel and Baillargeon, 2005; Destuynder, 1999):

$$
\hat{\mathrm{c}}=\left[\begin{array}{cccccc}
\mathrm{c}_{11} & \mathrm{c}_{12} & \mathrm{c}_{13} & \mathrm{c}_{14} & 0 & 0 \\
\mathrm{c}_{12} & \mathrm{c}_{11} & \mathrm{c}_{13} & -\mathrm{c}_{14} & 0 & 0 \\
\mathrm{c}_{13} & \mathrm{c}_{13} & \mathrm{c}_{33} & 0 & 0 & 0 \\
\mathrm{c}_{14} & -\mathrm{c}_{14} & 0 & \mathrm{c}_{44} & 0 & 0 \\
0 & 0 & 0 & 0 & \mathrm{c}_{44} & \mathrm{c}_{14} \\
0 & 0 & 0 & 0 & \mathrm{c}_{14} & \mathrm{c}_{66}
\end{array}\right]
$$

the piezoelectric moduli tensor Equation 2:

$$
\hat{\mathrm{e}}=\left[\begin{array}{ccc}
0 & -\mathrm{e}_{22} & \mathrm{e}_{31} \\
0 & \mathrm{e}_{22} & \mathrm{e}_{31} \\
0 & 0 & \mathrm{e}_{33} \\
0 & \mathrm{e}_{15} & 0 \\
\mathrm{e}_{15} & 0 & 0 \\
-\mathrm{e}_{22} & 0 & 0
\end{array}\right]
$$

and the strain tensor Equation 3:

$$
\hat{\mathrm{s}}=\left[\begin{array}{c}
0 \\
\mathrm{~s}_{22} \\
0 \\
0 \\
0 \\
\mathrm{~s}_{12}
\end{array}\right]
$$

Where:

$$
\mathrm{s}_{22}=\frac{\partial \mathrm{u}}{\partial \mathrm{z}}, \mathrm{s}_{12}=\frac{1}{\mathrm{R}_{\mathrm{p}}} \frac{\partial \mathrm{u}}{\partial \theta}
$$

Here $\mathrm{u}$ is mechanical displacement along the $\mathrm{z}$-axis. Introducing the electric field components $\left(\mathrm{E}_{1}, \mathrm{E}_{2}, \mathrm{E}_{3}\right)$ in cylindrical coordinates as $\left(\mathrm{E}_{\theta}, \mathrm{E}_{\mathrm{z}}, \mathrm{E}_{\mathrm{r}}\right)$ and making use the constitutive relation Equation 4:

$\hat{T}=\hat{c} \hat{s}-\hat{e} \vec{E}$

One can obtain the tensor elements of stress tensor $\mathrm{T}_{\mathrm{ij}}$ in terms of $E_{z}=-\frac{\partial \phi}{\partial z}$ and mechanical displacement $u$ in cylindrical coordinates as the following form Equation 5:

$$
\left\{\begin{array}{l}
\mathrm{T}_{\theta \theta}=\mathrm{c}_{12} \frac{\partial \mathrm{u}}{\partial \mathrm{z}}-\mathrm{e}_{12} \frac{\partial \phi}{\partial \mathrm{z}} \\
\mathrm{T}_{\mathrm{zz}}=\mathrm{c}_{11} \frac{\partial \mathrm{u}}{\partial \mathrm{z}}+\mathrm{e}_{22} \frac{\partial \phi}{\partial \mathrm{z}}, \\
\mathrm{T}_{\mathrm{rr}}=\mathrm{c}_{13} \frac{\partial \mathrm{u}}{\partial \mathrm{z}}, \\
\mathrm{T}_{\mathrm{rz}}=-\mathrm{c}_{14} \frac{\partial \mathrm{u}}{\partial \mathrm{z}}+\mathrm{e}_{15} \frac{\partial \phi}{\partial \mathrm{z}}, \\
\mathrm{T}_{\mathrm{r} \theta}=\mathrm{c}_{14} \frac{1}{\mathrm{R}_{\mathrm{p}}} \frac{\partial \mathrm{u}}{\partial \theta}, \\
\mathrm{T}_{\theta \mathrm{z}}=\mathrm{c}_{66} \frac{1}{\mathrm{R}_{\mathrm{p}}} \frac{\partial \mathrm{u}}{\partial \theta}
\end{array}\right\}
$$




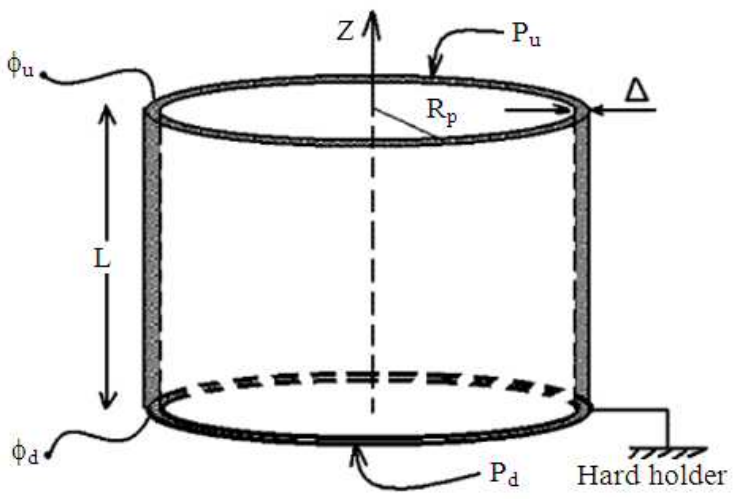

Fig. 1. Sketch of an annular cylindrical piezoelectric shell biased by electrostatic potential and hydrostatic pressure its symmetric axis

The governing equations for balance of linear momentum:

$$
\mathrm{T}_{\mathrm{i}, \mathrm{i}}=\rho \ddot{\mu}_{\mathrm{j}}
$$

and balance of electrical displacement vector with material properties:

$$
\overrightarrow{\mathrm{D}}=\hat{\varepsilon} \overrightarrow{\mathrm{E}}+\hat{\mathrm{e}} \hat{\mathrm{s}}
$$

In cylindrical coordinates for piezoelectric region result Equation 6 and 7:

$\mathrm{T}_{\mathrm{rz}, \mathrm{r}}+\mathrm{T}_{\theta z, \theta}+\mathrm{T}_{\mathrm{zz}, \mathrm{z}}=\mathrm{pu}_{\mathrm{z}}$

$\mathrm{D}_{\theta}=\mathrm{e}_{22} \frac{1}{\mathrm{R}_{\mathrm{p}}} \frac{\partial \mathrm{u}}{\partial \theta}, \mathrm{D}_{\mathrm{r}}=\mathrm{e}_{31} \frac{\partial \mathrm{u}}{\partial \mathrm{z}}$

$\mathrm{D}_{\mathrm{z}}=-\varepsilon_{11} \frac{\partial \phi}{\partial \mathrm{z}}+\mathrm{e}_{22} \frac{\partial \mathrm{u}}{\partial \mathrm{z}}$

where, in the above equations $\hat{\varepsilon}$ is dielectric permittivity at constant strain. It must be noted that the buckling effect is negligible when the radius of thin shells to be much greater than their length. Therefore the radial displacements respect to the longitudinal displacements are neglected (Popow, 1968; Timoshenko and Woinowsky-Krieger, 1959). Here by substituting:

$$
u=u(z) e^{i m \theta} e^{i \omega t}, \phi=\phi(z) e^{i m \theta} e^{i \omega t}
$$

into the relations (5-7) and using $\vec{\Delta} \cdot \vec{D}=0$ we obtain a couple system of second order ordinary differential equations for the longitudinal displacement $\mathrm{u}$ and electric potential $\phi$. These differential equations have the following form Equation 8 and 9:

$$
\begin{aligned}
& \frac{d^{2} u(z)}{d z^{2}}+\left(\frac{p \omega^{2}}{c_{11}}-\frac{m^{2}}{R_{p}^{2}} \frac{c_{66}}{c_{11}}\right) u(z)+\frac{e_{22}}{c_{11}} \frac{d^{2} \phi(z)}{d^{2}}=0 \\
& \frac{d^{2} \phi(z)}{d z^{2}}-\frac{e_{22}}{\varepsilon_{11}}\left(\frac{m^{2}}{R_{p}^{2}} u(z)+\frac{d^{2} u(z)}{d^{2}}\right)=0
\end{aligned}
$$

The detailed computations for independence on the radial coordinate are presented in the appendix part. In Equation (8-9) the tensor elements $e_{i j}, c_{i j}$ and $\epsilon_{i j}$ are the piezoelectric moduli in unit Coulombs/meter ${ }^{2}$, the elastic stiff-nesses in unit $\mathrm{Pa}$ and dielectric permittivity at constant strain in unit Farads/meter, respectively. The general solutions of Equation (8 and 9) have the following form Equation 10:

$$
\begin{aligned}
\mathrm{u}(\mathrm{z}) & =\mathrm{A} \sin (\mathrm{kz})+\mathrm{B} \cos (\mathrm{kz}), \\
\phi(\mathrm{z}) & =\frac{\mathrm{e}_{22}}{\varepsilon_{11}}\left(1-\frac{\mathrm{m}^{2}}{\mathrm{R}_{\mathrm{p}}^{2} \mathrm{k}^{2}}\right)[\mathrm{A} \sin (\mathrm{kz})+\mathrm{B} \cos (\mathrm{kz})]+\mathrm{Cz}+\mathrm{D}
\end{aligned}
$$

where, A, B, C, D Are arbitrary constants and Equation 11:

$\mathrm{k}^{2}=\frac{\rho \omega^{2}+\frac{\mathrm{m}^{2}}{\mathrm{R}_{\mathrm{p}}^{2}}\left(\mathrm{e}_{22}^{2} / \varepsilon_{11}-\mathrm{c}_{66}\right)}{\mathrm{c}_{11}+\mathrm{e}_{22}^{2} / \varepsilon_{11}}$

Substituting the general solutions (10) in Equation (6) the stress element $T_{z z}$ can expressed as Equation 12:

$$
\begin{gathered}
\mathrm{T}_{\mathrm{Zz}}=\mathrm{Ce}_{22}+\mathrm{kc}_{11}(\mathrm{~A} \cos (\mathrm{kz})-\mathrm{B} \sin (\mathrm{kz})) \\
+\frac{\mathrm{ke}_{22}^{2}}{\varepsilon_{11}}\left(1-\frac{\mathrm{m}^{2}}{\mathrm{R}_{\mathrm{p}}^{2} \mathrm{k}^{2}}\right)(\mathrm{A} \cos (\mathrm{kz})-\mathrm{B} \sin (\mathrm{kz})) \\
\text { 3. GRAPHS OF FREQUENCY } \\
\text { SPECTRUM AND MECHANICAL } \\
\text { DISPLACEMENT }
\end{gathered}
$$

\section{GRAPHS OF FREQUENCY DISPLACEMENT}

In this section we will use the following boundary conditions for obtaining the special solutions of Equation (8-9) and the coefficient k Equation 13: 


$$
\begin{aligned}
& \left.\mathrm{u}(\mathrm{z})\right|_{\mathrm{z}=\mathrm{o}}=0, \\
& \left.\phi(\mathrm{z})\right|_{\mathrm{z}=\mathrm{o}}=\phi_{\mathrm{d}}, \\
& \left.\phi(\mathrm{z})\right|_{\mathrm{z}=\mathrm{L}}=\phi_{\mathrm{u}}, \\
& \mathrm{T}_{\mathrm{zz} \mid \mathrm{z}=0}=\mathrm{p}_{\mathrm{d}}, \\
& \mathrm{T}_{\mathrm{zz} \mid \mathrm{z}=\mathrm{L}}=\mathrm{P}_{\mathrm{u}}
\end{aligned}
$$

Taking into the account boundary conditions (13) the coefficients directly are determined as Equation 14:

$$
\begin{aligned}
& \mathrm{B}=0, \\
& \mathrm{D}=\phi_{\mathrm{d}} \\
& \mathrm{C}=\frac{\mathrm{p}_{\mathrm{d}}}{\mathrm{e}_{22}}-\frac{\mathrm{p}_{\mathrm{u}}-\mathrm{p}_{\mathrm{d}}}{\mathrm{e}_{22(\cos (\mathrm{KL})-1)}} \\
& \mathrm{A}=\frac{\mathrm{p}_{\mathrm{u}-\mathrm{p}_{\mathrm{d}}}}{\mathrm{k}(\cos (\mathrm{kL})-1)\left(\mathrm{c}_{11}+\frac{\varepsilon_{22}^{2}}{\varepsilon_{11}}\left(1-\frac{\mathrm{m}^{2}}{\mathrm{R}_{\mathrm{p}}^{2} \mathrm{k}^{2}}\right)\right)}
\end{aligned}
$$

and the parameter $\mathrm{k}$ will appear in an implicit function as Equation 15:

$$
\begin{aligned}
& 1+\left(\cos (k L)-1\left(\frac{\mathrm{e}_{22}\left(\phi_{\mathrm{u}}-\phi_{\mathrm{d}}\right)-\mathrm{P}_{\mathrm{d}} \mathrm{L}}{\mathrm{L}\left(\mathrm{p}_{\mathrm{u}}-\mathrm{p}_{\mathrm{d}}\right)}\right)\right. \\
& -\frac{\sin (\mathrm{kL})}{\mathrm{k}}\left(\frac{\mathrm{e}_{22}}{\mathrm{~L} \varepsilon_{11}} \frac{1-\frac{\mathrm{m}^{2}}{\mathrm{R}_{\mathrm{p}}^{2} \mathrm{k}^{2}}}{\left.\mathrm{c}_{11}+\frac{\varepsilon_{22}^{2}}{\varepsilon_{11}}\left(1-\frac{\mathrm{m}^{2}}{\mathrm{R}_{\mathrm{p}}^{2} \mathrm{k}^{2}}\right)\right)}\right)=0
\end{aligned}
$$

The detailed computations are presented in the appendix part. In other word, the Equation (11) and (15) present the permission frequency of vibrations along the axis for a fixed configuration. In continuation of our discussion we will present several graphs of permission frequency and amplitude of mechanical displacement for several configurations. It must be noted that our date refer to $\mathrm{L}_{\mathrm{i}} \mathrm{TaO}_{3}$ (one of trigonal $(3 \mathrm{~m}$ ) crystals) with mass density $\rho=7454 \mathrm{Kg} / \mathrm{m}^{3}$ at temperature $25^{\circ} \mathrm{C}$. For this crystal we have (Zelenka, 1986):

$$
\begin{aligned}
& \mathrm{e}_{22}=1.59 \mathrm{C} / \mathrm{m}^{2}, \mathrm{c}_{11}=229.8 \times 10^{9} \mathrm{~N} / \mathrm{m}^{2}, \\
& \mathrm{c}_{66}=92.9 \times 10^{9} \mathrm{~N} / \mathrm{m}^{2}, \varepsilon_{11}=339.5 \times 10^{-12=} \mathrm{F} / \mathrm{m}^{2}
\end{aligned}
$$

Figure 2 illustrates the permission frequency of axial mechanical vibrations versus the length of the piezoelectric tube L. In this figure both the up and down pressures and the difference of electrostatic potentials are fix. The graphs in Fig. 2 have shown for non-symmetric mode $\mathrm{m}=2$ and several mean radii of tube. As it shows the frequency decreases by increasing the radius of tube in a fix length of tube. Furthermore, numerical computations show that the variations of frequency for higher order of $\mathrm{m}$ are considerable. As the Fig. 3 shows the frequency of axial mechanical vibrations increases by increasing difference of electrostatic potentials.

For fixed configuration the higher frequency refers to the higher order of $m$ as shown in Fig. 4. The effects of hydrostatic pressure of lower part $\mathrm{P}_{\mathrm{d}}$ on frequency are illustrated in Fig. 5. As it shows for a fix configuration the frequency of axial mechanical vibrations decreases by increasing $\mathrm{P}_{\mathrm{d}}$. Comparing all the Fig. 2-5 shows that in all cases the frequency decrease by increasing tube length L. Figure 6-10 present variations amplitude of mechanical vibrations A versus the operating frequency. As shown in Fig. 6 for a fix configuration the amplitude decreases by increasing the radius of tube in a fix frequency. Furthermore, Fig. 7 shows that amplitude increases by increasing the difference of electrostatic potentials in a fix operating frequency and configuration. The amplitude decrease by increasing length of tube as shown in Fig. 8. Figure 9 shows that for fixed operating frequency and configuration the greater amplitudes coincident with large number of $\mathrm{m}$. Finally, Fig. 10 illustrates that the amplitude decrease by increasing the hydrostatic pressure $P_{d}$. In Fig. 6-10 as they shown the amplitude decreases by increasing the frequency of mechanical vibration for all configurations.

\section{APPENDIX}

By taking in to account radial depending of $\mathrm{u}(\mathrm{z})$ as $\mathrm{u}(\mathrm{r}, \mathrm{z})$ from dynamics equation we have:

$$
\begin{aligned}
& \frac{\partial^{2} \mathrm{u}(\mathrm{r}, \mathrm{z})}{\partial \mathrm{z}^{2}}+\left(\frac{\mathrm{p} \omega^{2}}{\mathrm{c}_{11}}-\frac{\mathrm{m}^{2}}{\mathrm{r}^{2}} \frac{\mathrm{c}_{66}}{\mathrm{c}_{11}}\right) \mathrm{u}(\mathrm{r}, \mathrm{z})+\frac{\mathrm{e}_{22}}{\mathrm{c}_{11}} \frac{\partial^{2} \phi(\mathrm{r}, \mathrm{z})}{\partial \mathrm{z}^{2}}- \\
& \frac{\mathrm{c}_{14}}{\mathrm{c}_{11}} \frac{\partial^{2}}{\partial \mathrm{r} \partial \mathrm{z}} \mathrm{u}(\mathrm{r}, \mathrm{z})+\frac{\mathrm{e}_{15}}{\mathrm{c}_{11}} \frac{\partial^{2}}{\partial \mathrm{r} \partial \mathrm{z}} \phi(\mathrm{r}, \mathrm{z})=0
\end{aligned}
$$

and from $\nabla . \mathrm{D}=0$ we will obtain:

$$
\frac{\partial^{2} \phi(r, z)}{\partial z^{2}}-\frac{e_{22}}{\varepsilon_{11}}\left(\frac{m^{2}}{r^{2}} u(r, z)+\frac{\partial^{2} u(r, z)}{\partial z^{2}}\right)-e_{31} \frac{\partial^{2}}{\partial r \partial z} u(r, z)=0
$$




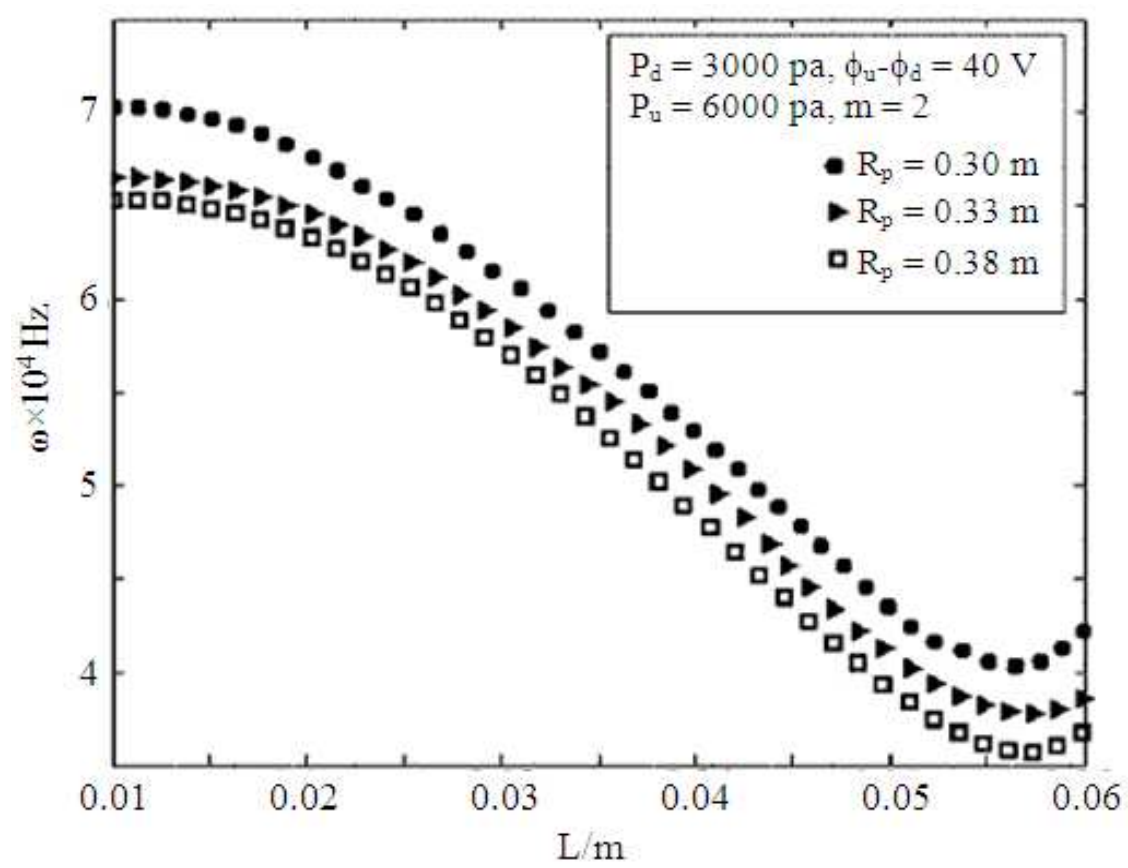

Fig. 2. Graph of frequency of longitudinal mechanical vibrations $\omega$ versus to length of the piezoelectric tube L, (L- $\omega)$ for several radii tube $\mathrm{R}_{\mathrm{p}}$

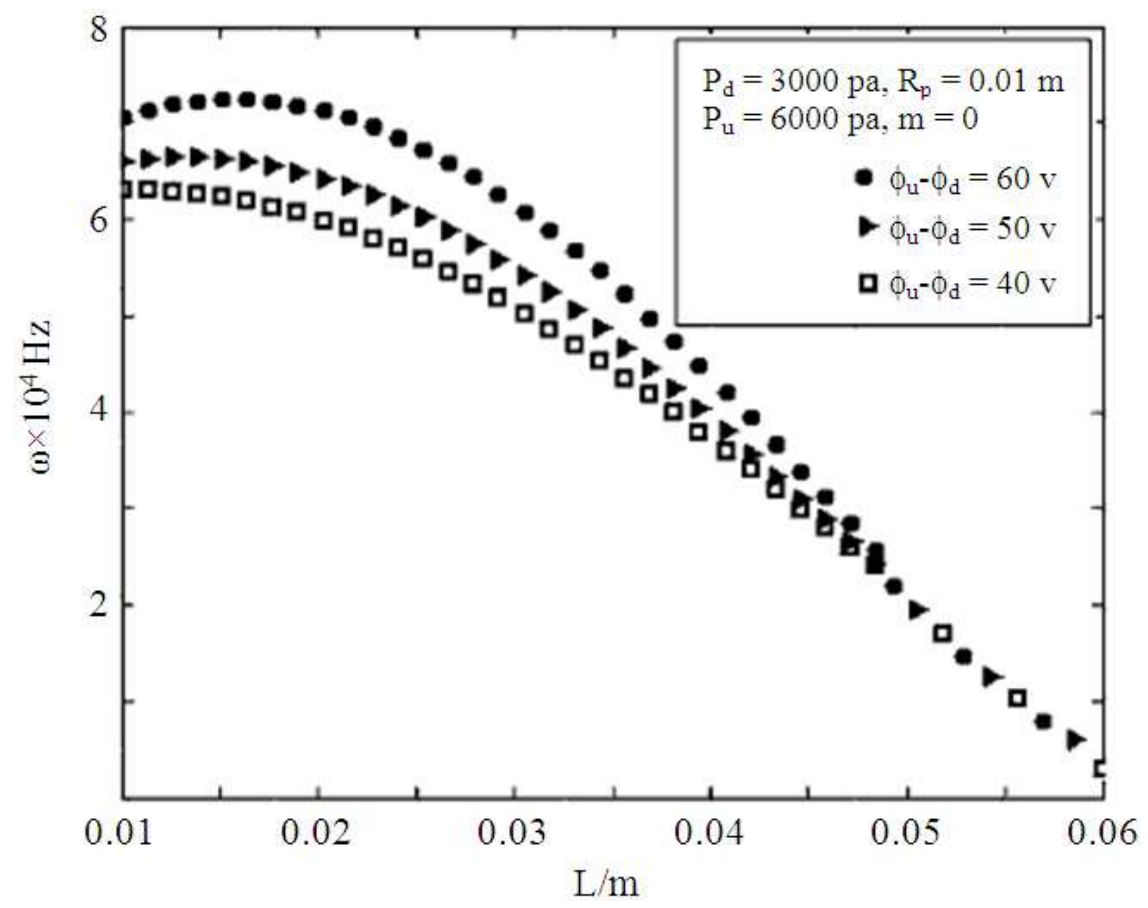

Fig. 3. Graph of $(L-\omega)$ for several longitudinal voltages loading $\phi_{u}-\phi_{d}$ 
H. Zeynali et al. / Physics International 4 (1): 13-22, 2013

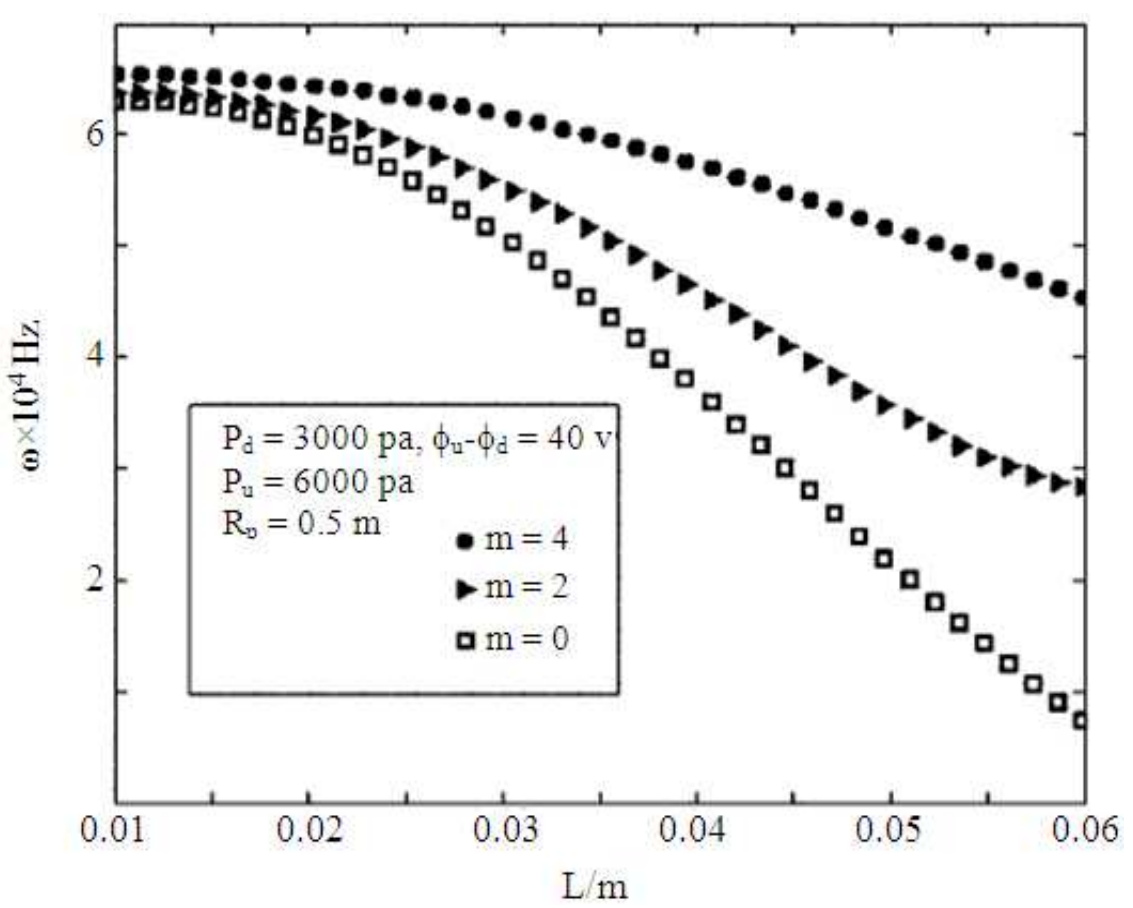

Fig. 4. Graph of (L- $\omega)$ for symmetric and non-symmetric modes

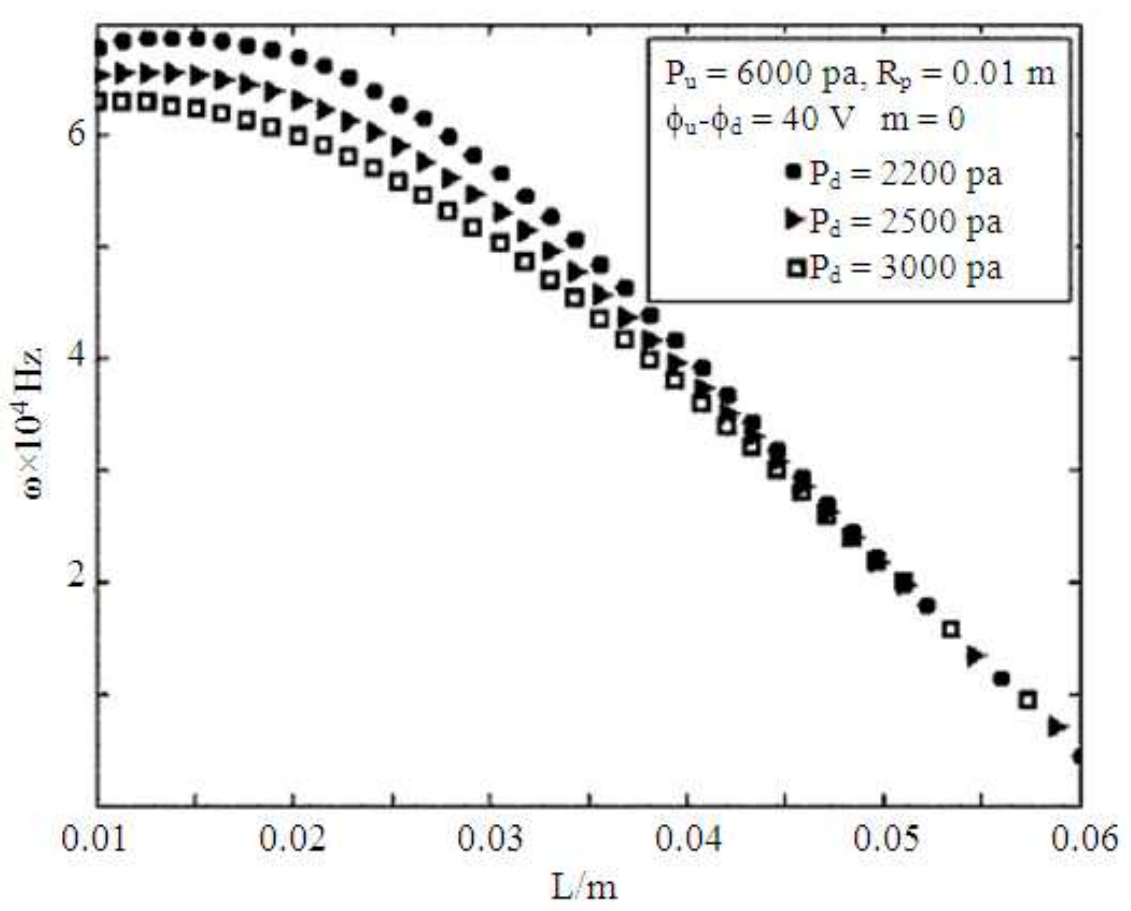

Fig. 5. The hydrostatic pressure effects on graph of $(\mathrm{L}-\omega)$ 
H. Zeynali et al. / Physics International 4 (1): 13-22, 2013

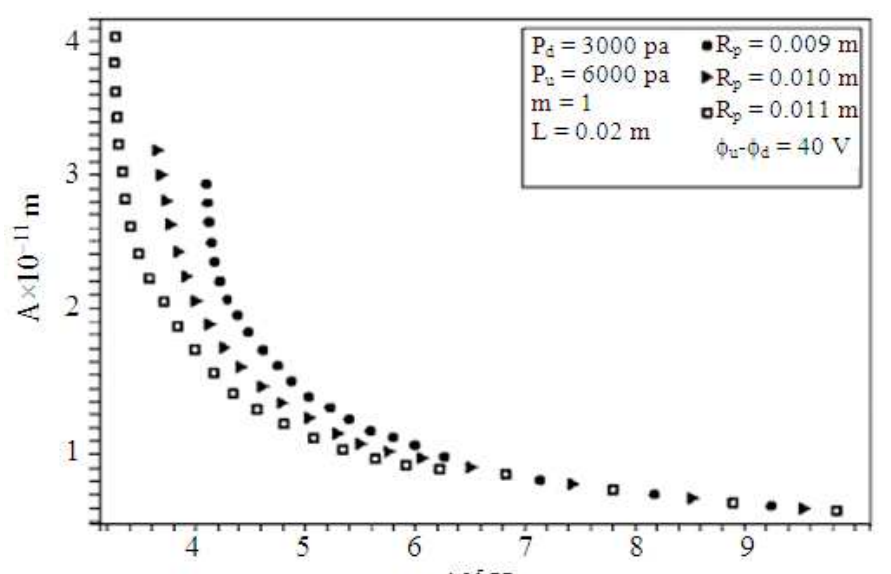

$\omega \times 10^{5} \mathrm{~Hz}$

Fig. 6. Graph of amplitude of longitudinal mechanical vibrations a versus the frequency of oscillations $\omega$, $(\omega$-A) for several radii of tube $R_{p}$

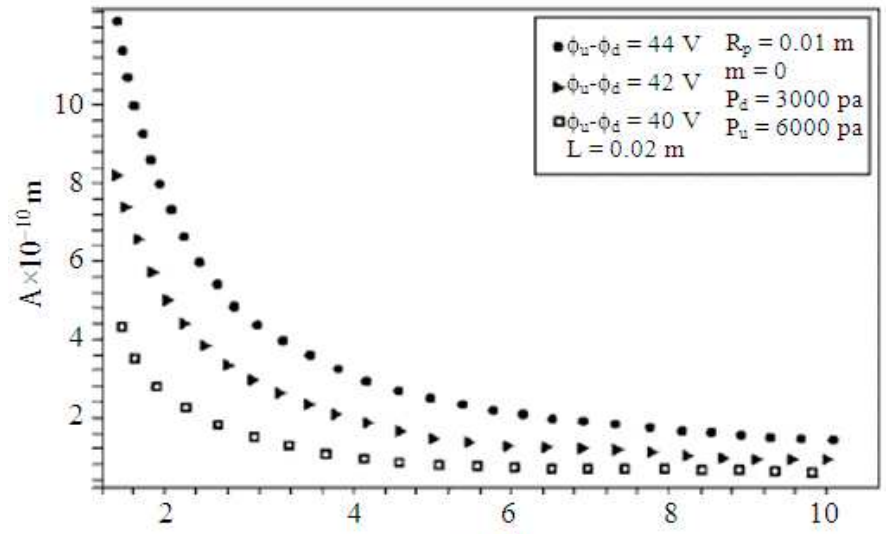

$\omega \times 10^{4} \mathrm{~Hz}$

Fig. 7. Graph of $(\omega-\mathrm{A})$ for several longitudinal voltages loading $\phi_{\mathrm{u}}-\phi_{\mathrm{d}}$

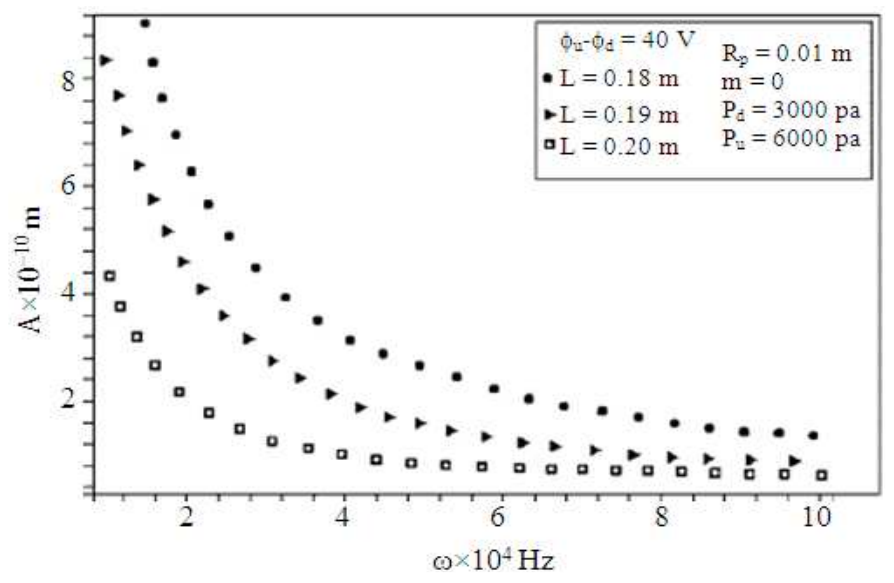

Fig. 8. Graph of ( $\omega-A)$ for several tube length $L$ 


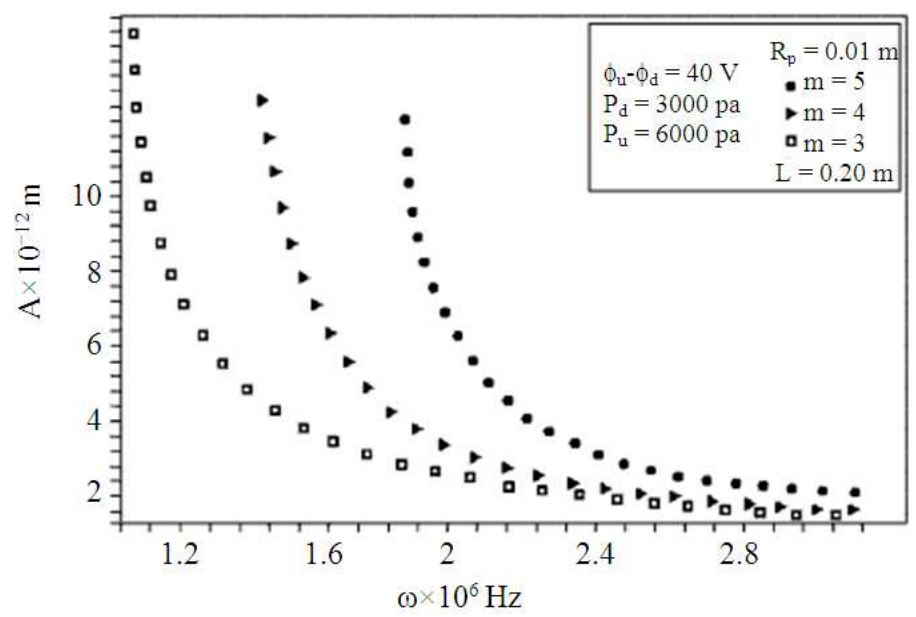

Fig. 9. Graph of ( $\omega$-A) for symmetric and non-symmetric modes

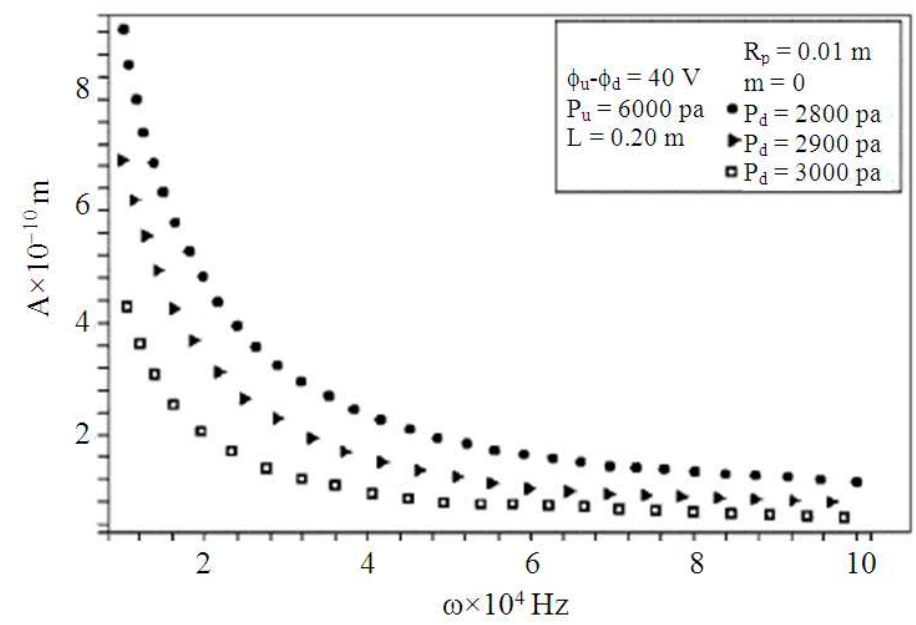

Fig. 10. The hydrostatic pressure effects on $(\omega-\mathrm{A})$ graph

By averaging $\nabla . D=0$ in across of thickness of shell between $r=R_{p}$ (inner radius) and $r=R_{p}+\Delta$ (outer radius) for a fixed value of $\mathrm{z}$ and taking $\mathrm{u}(\mathrm{r}, \mathrm{z})=\mathrm{R}_{1}(\mathrm{r}) \mathrm{Z}_{1}(\mathrm{z})$, $\phi(r, \quad \mathrm{z})=\mathrm{R}_{2}(\mathrm{r}) \quad \mathrm{Z}_{2}(\mathrm{z})$ and introducing $\beta=$ $\mathrm{e}_{31} \frac{\partial^{2}}{\partial \mathrm{r} \partial \mathrm{z}} \mathrm{u}(\mathrm{r}, \mathrm{z})$ we will obtain:

$$
\begin{aligned}
& \langle\beta\rangle=\frac{1}{\Delta} \int_{\mathrm{R}_{\mathrm{p}}}^{\mathrm{R}_{\mathrm{p}}+\Delta} \beta \mathrm{dr} \propto\left\{\frac{\mathrm{d}^{2}}{\mathrm{dz}^{2}} \mathrm{Z}_{2}(\mathrm{z}) \frac{1}{\Delta} \int_{\mathrm{R}_{\mathrm{p}}}^{\mathrm{R}_{\mathrm{p}}+\Delta} \mathrm{R}_{2}(\mathrm{r}) \mathrm{dr}, \mathrm{z}_{1}(\mathrm{z}) \frac{1}{\Delta}\right. \\
& \left.\int_{\mathrm{R}_{\mathrm{p}}}^{\mathrm{R}_{\mathrm{p}}+\Delta} \frac{\mathrm{R}_{1}(\mathrm{r})}{\mathrm{r}^{2}} \mathrm{dr}, \frac{\mathrm{d}^{2}}{\mathrm{dz}^{2}} \mathrm{Z}_{1}(\mathrm{z}) \frac{1}{\Delta} \int_{\mathrm{R}_{\mathrm{p}}}^{\mathrm{R}_{\mathrm{p}}+\Delta} \mathrm{R}_{1}(\mathrm{r}) \mathrm{dr}\right\}
\end{aligned}
$$

Generally in the problems including cylindrical configuration $\mathrm{R}_{1}(\mathrm{r})$ and $\mathrm{R}_{2}(\mathrm{r})$ are in order of series of ordinary Bessel and Neumann functions $\left(\mathrm{J}_{\mathrm{m}}, \mathrm{N}_{\mathrm{m}}\right)$ of the $\mathrm{m}$ order where $\mathrm{m}$ is the order of angular dependence of displacement and potential function. Therefore it is easy to see that (Arfken et al., 2011):

$$
\left\{\begin{array}{l}
\lim _{\Delta \rightarrow 0} \frac{\mathrm{d}^{2}}{\mathrm{dz}^{2}} \mathrm{Z}_{2}(\mathrm{z}) \frac{1}{\Delta} \int_{\mathrm{R}_{\mathrm{p}}}^{\mathrm{Rp}+\Delta} \mathrm{R}_{2}(\mathrm{r}) \mathrm{dr}=0, \lim _{\Delta \rightarrow 0} \mathrm{Z}_{1}(\mathrm{z}) \frac{1}{\Delta} \\
\int_{\mathrm{R}_{\mathrm{p}}}^{\mathrm{R}_{\mathrm{p}}+\Delta} \frac{\mathrm{R}_{1}(\mathrm{r})}{\mathrm{r}^{2}}=0, \lim _{\Delta \rightarrow 0} \frac{\mathrm{d}^{2}}{\mathrm{dz}^{2}} \mathrm{Z}_{1}(\mathrm{z}) \frac{1}{\Delta} \int_{\mathrm{R}_{\mathrm{p}}}^{\mathrm{R}_{\mathrm{p}}+\Delta} \mathrm{R}_{1}(\mathrm{r}) \mathrm{dr}=0
\end{array}\right\}
$$

From the above results we will obtain:

$$
\langle\beta\rangle=\left\langle\frac{\partial^{2} u}{\partial r \partial z}\right\rangle=0
$$


Taking in to account the above results and using them in average of dynamic equation one can find that:

$$
\left\langle\frac{\partial^{2} \phi}{\partial \mathrm{r} \partial \mathrm{z}}\right\rangle=0
$$

The two above results let us to neglect the radial coordinate dependence of $u$ and $\phi$ in governing equation. About using the boundary conditions (13) and details for obtaining the Equation (15) it must be noted we need to determine the coefficients A, B, C, D and k.

From $\mathrm{u}(\mathrm{z}=0)=0$ we will find $\mathrm{B}=0$ and from $\phi(\mathrm{z})_{\mid \mathrm{z}=\mathrm{o}}=\phi_{\mathrm{d}}$ we have $\mathrm{D}=\phi_{\mathrm{d}}$. Furthermore:

$$
\begin{gathered}
\phi(\mathrm{z})_{\mid \mathrm{z}=\mathrm{L}}=\phi_{\mathrm{u}} \Rightarrow \phi_{\mathrm{u}}=\phi_{\mathrm{a}}+\mathrm{CL}+\frac{\mathrm{e}_{22}}{\varepsilon_{11}} \mathrm{~A} \sin (\mathrm{kL})\left[1-\frac{\mathrm{m}^{2}}{\mathrm{R}_{\mathrm{p}}^{2} \mathrm{k}^{2}}\right], \\
\mathrm{T}_{\mathrm{zz} \mid \mathrm{z}=0}=\mathrm{P}_{\mathrm{d}} \Rightarrow \mathrm{P}_{\mathrm{d}}=\mathrm{e}_{22} \mathrm{C}+\mathrm{Ak}\left\{\mathrm{c}_{11}+\frac{\mathrm{e}_{22}^{2}}{\varepsilon_{11}}\left[1-\frac{\mathrm{m}^{2}}{\mathrm{R}_{\mathrm{p}}^{2} \mathrm{k}^{2}}\right]\right\}, \\
\mathrm{T}_{\mathrm{zz} \mid \mathrm{z}=\mathrm{L}}=\mathrm{P}_{\mathrm{u}} \Rightarrow \mathrm{p}_{\mathrm{u}}=\mathrm{e}_{22} \mathrm{C}+\mathrm{kA} \cos (\mathrm{kL})\left\{\mathrm{c}_{11}+\frac{\mathrm{e}_{22}^{2}}{\varepsilon_{11}}\left[1-\frac{\mathrm{m}^{2}}{\mathrm{R}_{\mathrm{p}}^{2} \mathrm{k}^{2}}\right]\right\}
\end{gathered}
$$

Finally from three above equations we will find:

$$
\begin{aligned}
& \mathrm{A}=\frac{\mathrm{P}_{\mathrm{u}}-\mathrm{P}_{\mathrm{d}}}{\mathrm{k}(\cos (\mathrm{kL})-1)\left\{\mathrm{c}_{11}-\frac{\varepsilon_{22}^{2}}{\varepsilon_{11}}\left[1-\frac{\mathrm{m}^{2}}{\mathrm{R}_{\mathrm{p}}^{2} \mathrm{k}^{2}}\right]\right\}}, \\
& \mathrm{C}=\frac{\mathrm{P}_{\mathrm{d}}}{\mathrm{e}_{22}}-\frac{\mathrm{P}_{\mathrm{u}}-\mathrm{P}_{\mathrm{d}}}{\mathrm{e}_{22}(\cos (\mathrm{kL})-1),} \\
& \phi_{\mathrm{u}}-\phi_{\mathrm{d}}=\frac{\mathrm{P}_{\mathrm{d}} \mathrm{L}}{\mathrm{e}_{22}}-\frac{\mathrm{L}\left(\mathrm{P}_{\mathrm{u}}-\mathrm{P}_{\mathrm{d}}\right)}{\mathrm{e}_{22}(\cos (\mathrm{kL})-1)}+ \\
& \frac{\mathrm{e}_{22}}{\varepsilon_{11}} \frac{\left(1-\frac{\mathrm{m}^{2}}{\mathrm{R}_{\mathrm{p}}^{2} \mathrm{k}^{2}}\right)\left(\mathrm{p}_{\mathrm{u}}-\mathrm{P}_{\mathrm{d}}\right) \sin (\mathrm{kL})}{\mathrm{k}(\cos (\mathrm{kL})-1)\left\{\mathrm{c}_{11}+\frac{\mathrm{e}_{22}^{2}}{\varepsilon_{11}}\left(1-\frac{\mathrm{m}^{2}}{\mathrm{R}_{\mathrm{p}}^{2} \mathrm{k}^{2}}\right)\right\}}
\end{aligned}
$$

\section{CONCLUSION}

In this study we have reviewed a combined electromechanical problem for axially polarized of an annular cylindrical piezoelectric made of trigonal (3M) crystals. We applied new boundary conditions and we obtained a frequency spectrum of axial mechanical vibrations as an implicit function including the axial hydrostatic pressures, axial electrostatic potential and geometrical dimensions. We have shown that the frequency of axial mechanical vibrations increases by increasing the difference of electrostatic potential and order of azimuthal dependence $\mathrm{m}$. Furthermore, we have obtained the frequency decreases by increasing the radius of tube and hydrostatic pressure. The graphs of amplitude of vibrations versus the operating frequency have been presented. They have been shown that the amplitude decreases by increasing radius of tube and its length and the hydrostatic pressure. So it has been shown that the amplitude increases by increasing the electrostatic potential and order of magnitude of azimuthal dependence $\mathrm{m}$.

\section{REFERENCES}

Arfken, G.B., H.J. Weber and F.E. Harris, 2011. Mathematical Methods for Physicists. 7th Edn., Academic Press, Burlington, ISBN-10: 0123846552, pp: 1220.

Bartlett, P.A., S.J. Eaton, J. Gore, W.J. Metheringham and A.G. Janner, 2001. High-power, low frequency magnetostrictive actuation for anti-vibration applications. Sens. Actuat. A: Phys., 91: 133-136. DOI: 10.1016/S0924-4247(01)00475-7

Brebbia, C.A., M. Marchetti and P. Santini, 1998. Computational Methods for Smart Structures and Materials. 1st Edn., Computational Mechanics, ISBN-10: 1853126004, pp: 304.

Destuynder, P., 1999. A Few Remarks on the Controllability of an Aeroacoustic Model using Piezodevices. In: Smart Structures, Holnickis-zulc, J. and J. Rodellar (Eds.), Springer, Dordrecht, ISBN10: 0792356128, pp: 53-62.

Ebenzer, D.D. and R. Ramesh, 2003. Exact analysis of axially polarized piezoelectric ceramic cylinders with certain uniform boundary conditions. Curr. Sci., 85: 1173-1179.

Feriedom, M., 1968. The use of piezoelectric probes for direct measurement of plasma pressure. Plasma Phys., 10: 561-561. DOI: 10.1088/0032-1028/10/5/408

Gabbert, U. and H. Tzon, 2001. Smart structures and structures system. Proceedings of the IUTAMSymposium, (IUTAM-S’ 01), Magdeburg, Kluwer.

Gafsi, R., A. Malik, F. Ahdad, P. Lecoy and J. Bures, 1997. Static stress optical-fiber sensor. Sens. Actuat. A: Phys., 62: 501-505. DOI: 10.1016/S09244247(97)01528-8

Haskins, J.F. and J.L. Walsh, 1957. Vibrations of ferroelectric cylindrical shells with transverse isotropy. I. Radially polarized case. J. Acoust. Soc. Am., 29: 729-734. 
Hison, C., G. Ausanio, A.C. Barone, V. Lannotti and E. Pepe et al., 2005. Magnetoelastic sensor for realtime monitoring of elastic deformation and fracture alarm. Sens. Actuat. A: Phys., 125: 10-14. DOI: 10.1016/j.sna.2005.05.019

Inaudi, D., A. Elamari, L. pflug, N. Gisin and J. Breguet et al., 1994. Low-coherence deformation sensors for the monitoring of civil-engineering structures. Sens. Actuat. A: Phys., 44: 125-130. DOI: 10.1016/09244247(94)00797-7

Jazi, B., B. Khoshnevisan and H. Zeynali, 2006. The theoretical simulation of magnetized electron beam effects on radially polarized of an annular cylindrical piezoelectric crystal. Phys. Lett. A, 358: 149-153. DOI: 10.1016/j.physleta.2006.05.001

Kawiecki, G., 1999. Piezogenerated Elastic Waves for Structural Health Monitoring. In: Smart Structures, Holnicki-szulc, J. and J. Rodellar (Eds.), Springer, Dordrecht, ISBN-10: 0792356128, pp: 133-142.

Kraus, L., J. Bydovsk and P. Vec, 2003. Continuous stress annealing of amorphous ribbons for strain sensing applications. Sens. Actuat. A, 106: 117-120. DOI: 10.1016/S0924-4247(03)00147-X

Pasquale, M., 2003. Mechanical sensors and actuators. Sens. Actuat. A: Phys., 106: 142-148. DOI: 10.1016/S0924-4247(03)00153-5
Popow, E., 1968. Introduction to Mechanics of Solids. 1st Edn., Prentice-Hall, Englewood Cliffs, pp: 571.

Shud'ga, N.A., A.Y. Grigorenko and I.A. Loza, 1984. Axisymmetric electroelastic waves in a hollow piezoelectric ceramic cylinder. Soviet Applied Mechan., 20: 26-32. DOI: 10.1007/BF00883567

Stansfield, D., 1991. Underwater Electroacoustic Transducers. 1st Edn., Bath University Press, Bath, ISBN-10: 0861970829, pp: 413.

Timoshenko, S. and S. Woinowsky-Krieger, 1959. Theory of Plates and Shells. 1st Edn., McGraw-Hill, Auckland, pp: 580.

Vel, S.S. and B.P. Baillargeon, 2005. Analysis of static deformation, vibration and active damping of cylindrical composite shells with piezoelectric shear actuators. J. Vib. Acoust., 127: 395-407. DOI: $10.1115 / 1.1898337$

Wilson, O.B., 1988. Introduction to Theory and Design of Sonar Transducers. 1st Edn., Peninsula, Los Altos, ISBN-10: 0932146228, pp: 191.

Yang, J.S. and R.C. Batra, 1995. Thickness shear vibrations of a circular cylindrical piezoelectric shell. J. Acoust. Soc. Am., 97: 309-312.

Zelenka, J. 1986. Piezoelectric Resonators and Their Applications. 1st Edn., Elsevier Science and Technology Books, Amsterdam, ISBN-10: 0444995161, pp: 301. 